\title{
Difference of brain cortical thickness and area of different lobes between fetuses with intrauterine growth restriction and control group assessed by 3 Tesla MRI
}

Behnaz Moradi, MD ${ }^{1}$,; Mahboobeh Shirazi, MD*; Zohreh Alibeigi nezhad, MD²; Nazanin Seyed Saadat, MD² ; Hassan Hashemi, MD²; Mohammad Ali Kazemi, MD²,4; Masoumeh Gity, $\mathrm{MD}^{2}$;Maryam Rahmani, MD² Hossein Ghanaati, $\mathrm{MD}^{2}$

${ }^{1}$ Department of Radiology, Yas Complex Hospital, Tehran University of Medical Sciences, Tehran, Iran.

${ }^{2}$ Department of radiology, Advanced Diagnostic and Interventional Radiology Research Center (ADIR), Imam Khomeini Hospital Complex, Tehran University of Medical Sciences, Tehran, Iran

${ }^{3}$ Maternal, Fetal and Neonatal Research Center, Yas Complex Hospital, Tehran University of Medical Sciences, Tehran, Iran

4 Department of Radiology, Amiralam Hospital, Tehran University of Medical Sciences, Tehran, Iran.

*Corresponding author:

Mahboobeh Shirazi; Maternal, Fetal and Neonatal Research Center, Yas Complex Hospital, North Nejatollahi Street, Tehran, Iran

E-mail: mahboobehshirazi4@gmail.com

Competing Interest Statement: The authors have declared no competing interest 


\title{
Difference of brain cortical thickness and area of different lobes between fetuses with intrauterine growth restriction and control group assessed by 3 Tesla MRI
}

\begin{abstract}
Background: Intrauterine growth restricted (IUGR) is a major factor of perinatal and long-term morbidity and is associated with abnormal fetal brain development but its pattern of brain involvement is still unknown.
\end{abstract}

Materials and Methods: 42 women with IUGR pregnancy and 28 women with normally-grown fetuses between 28-38 weeks underwent 3Tesla MRI. Cortical thickness was assessed in 4 regions and was corrected by biparietal diameter/2. Also, whole brain surface area (WBA) and areas of 6 brain regions were included and corrected by WBA.

Results: IUGR fetuses had significantly thinner cortical thickness in the insula and temporal lobes compared to the control group (0.034 vs 0.043 and 0.036 vs 0.047 respectively, $\mathrm{P}$ value of $<0.05)$. They had significantly reduced WBA (P value: 0.028 ). The corrected brain areas were not significantly different between groups except for the corrected areas of cerebellum and hippocampus which were increased in IUGR fetuses compared to the control group $(0.147$ vs $0.130,0.017$ vs 0.0125 respectively, $\mathrm{P}$ value of < $0.05)$.

Conclusion: IUGR fetuses had significantly thinner insular and temporal lobe cortex and smaller WBA compared to the control group. Among different brain regions, cerebellum and hippocampus were less affected by growth restriction in utero period.

Keyword: Brain imaging; Fetus; Intrauterine Growth Restriction; MRI 


\section{Background}

Intrauterine growth restriction (IUGR) occurs in 5-10\% of all pregnancies (1). IUGR is defined as a birth weight below the 10th percentile for gestational age and is mostly caused by placental insufficiency $(2,3)$.

Multiple pathophysiologic mechanisms occur during IUGR due to placental dysfunction (4). Following placental insufficiency, oxygen and nutrients transfer to the fetus is reduced, blood flow selectively redistributes to the vital organs including the brain, in contrary, blood flow supply other fetal organs is decreased (2). These hemodynamic changes cause recurrent hypoxemia episodes (4). Evidence shows an adverse effect of hypoxia on brain development along with cell number and size reduction and consequently whole brain weight loss (5). Ultrasound with Doppler evaluation are used in high risk pregnancies for detection of the severity of hypoxia (6).

IUGR is a major factor of perinatal and long-term morbidity and is associated with abnormal fetal brain development, cerebral palsy, mental retardation, neurological dysfunction in motor skill and cognitive disorder (7). These neurodevelopmental dysfunctions are correlated with certain neurostructural changes in the brain (8). These developmental changes are seen in both severe and mild IUGR (9).

There is a major challenge in the perinatal diagnosis of brain injury in IUGR pregnancies (10). MRI has recently opened up the possibility of determining the structural and morphometric differences between the brain structure of IUGR and appropriate growth for age (AGA) fetuses $(1,2)$ Regarding previous researches, the pattern of brain abnormalities associated with IUGR is still unknown $(11,12)$. 
Cortical development is a complex process that is affected by many factors (9). MRI in IUGR fetuses shows significant differences in brain volume and cortical characteristics such as gyrification pattern and cortical thickness $(8,13,14)$. Some studies found brain grey matter volume reduction especially in temporal and insular lobes (15).

There are few studies that measure brain cortical thickness and areas in IUGR fetuses. So, the aim of this study was to evaluate the effect of growth restriction on cortical thickness and areas of the fetal brain in different regions compared to controls by 3T MRI.

\section{Materials and Methods}

\section{Patient Population}

We prospectively studied a sample of 42 women with IUGR pregnancy and 28 normal fetuses in the control group with gestational age between 28-38 weeks. This study was performed in the imaging department of our hospitals between March 2017 and January 2019. All participants were given written informed consent and the study was approved by institutional board members.

Gestational age was measured based on the first-trimester crown-rump length in all fetuses. We defined our IUGR cases as fetal weight less than 10th percentile for gestational age by ultrasound and according to the reference data (16).

The control group was chosen from fetuses with fetal and postnatal weight $\geq 10$ percentile with similar gestational age to the IUGR group who referred for MRI of extra-CNS pathologies. Maternal demographic data and perinatal data including gestational biometry and weight at the time of MRI session, birth weight and pregnancy outcome after birth were recorded in study groups. MRI 
Exclusion criteria were the presence of congenital infection, multiple pregnancies, chromosomal abnormalities or suspicious genetic syndromes, chronic maternal disease, general contraindications for MRI and any structural or brain abnormalities that were detected on MRI. Because of fetal calvarium shaowing, ultrasound is not suitable modality for evaluation of brain lobe areas. On the other hand, ultrasound has not enough soft tissue resolution for differentiating cortex from white metter. Therefore, in this study we assess the brain charactristics of fetuses by fetal MRI. According to ACR guideline, exposure to the 3T magnetic fields used in the routine clinical MRI process has not any reproducible harmful effects on the developing fetus. Also by using rapid acquisition sequences and decrease the acquisition time we tried to decrease fetal exposure (17).

\section{Doppler Ultrasound}

Ultrasound examination was carried out using a transabdominal 2-6 MHz curved- array transducer (Affiniti 50, General imaging configuration, Philips ultrasound machine, USA) during the same week of MRI session.

Fetal umbilical artery (UA) and middle cerebral artery (MCA) pulsatility index (PI) were assessed and values $>95^{\text {th }}$ centile and $<5$ th centile considered abnormal respectively according to the reference chart (18). Abnormal cerebroplacental ratio (CPR) was defined as a value below the fifth centile. The mean of bilateral uterine artery (UtA) PI was measured by transabdominal sonography and values were considered abnormal when was greater than the 95th centile (19).

IUGR cases were subcategorized into two study groups due to IUGR severity: Group A: with severity sign as fetal weight less than the third percentile and/or abnormal UA or UtA PI and/or abnormal CPR. Group B: without above mentioned criteria.

\section{MRI protocol}


Fetal brain MRI was carried out at a 3T MR unit General Electric system (GE Healthcare, discovery 750 GEM), using a 16-channel phased-array coil. Brain MRI was performed within the same week of diagnosis of IUGR by ultrasound.

Imaging process performed after 4 hours of fasting and without sedation, while the patient was positioned in left lateral decubitus. The duration of brain MRI was around 20-30 minutes per case. The examination protocol applied to study patients included the single shot fast spin echo T2weighted sequences with slice thickness $4 \mathrm{~mm}$ with no gap, field of view $25-27 \mathrm{~cm}$, repetition time 1500 milliseconds, echo time 98 milliseconds, matrix 288 X192 mm, flip angle 180 degrees, and acquisition time 25 seconds. Brain MRI was taken at 3 different orthogonal planes. If motion artifact degradation had been detected, the sequence was repeated until a satisfactory image was obtained.

\section{MRI analysis}

Offline analysis of all morphologic and biometric brain measurements was performed on Infinite Picture Archiving and Communication System (PACS) by an experienced specialist. The radiologist was aware of the preliminary diagnosis of IUGR but not the subgroups. Brain biometry [biparietal diameter (BPD) and head circumference (HC)] were measured in the transthalamic axial plane and were assessed based on standard reference chart (16).

\section{Brain cortical thickness assessment}

Insular cortex thickness: in the axial plane just below the plane of cavum septum pellucidum; Frontal cortex thickness and occipital cortex thickness: in the axial plane at the level of cavum septum pellucidum; Temporal cortex thickness: In the coronal plane, just anterior slice to pons level. Two parts of it was measured from inner to outer. We calculated the average of bilateral cortical thickness for each region, then we corrected them by dividing by BPD/2 (Figure. 1). 


\section{Brain area assessment}

Occipital lobe area: in the first para-sagittal plane, near falx, posterior to the parieto-occipital sulcus; Temporal lobe area: in the coronal plane, just anterior to the pons level; Frontal lobe area: in the axial plane, just superior to cavum septum pellucidum and lateral ventricles, anterior to the Rolandic fissure; Parietal lobe area: in the axial plane, immediately superior to cavum septum pellucidum and lateral ventricles, posterior to the Rolandic fissure; Cerebellum: in the axial plane, at the level of the middle cerebellar peduncle; Pons: at the same level described for the cerebellum.; Midbrain: in the axial plane, at the level of the midbrain; Whole brain surface area (WBA): in the axial plane at the level of cavum septum pellucidum; Whole intracranial area: at the same level of WBA by tracing cursor inside the bony calvarium (Figure 2). A lot of effort was put into taking standard and motionless images and oblique images were omitted.

All measurements were delineated by cursor-guided free-hand trace and performed twice in which the mean of each one was used for analysis. Afterward, the mean of the bilateral area for each region was calculated. The corrected brain area was obtained by dividing each brain area by WBA and corrected WBA was calculated by dividing by whole intracranial area.

\section{Data analysis}

The software package SPSS 22 (IBM Corp., Armonk, NY, USA) was used for the statistical analyses. Data were summarized using means and SDs for quantitative variables and using frequencies and percentages for qualitative ones. In the data analysis, first, the normal distribution of quantitative data was investigated using the Kolmogorov-Smirnov test (K-S test). A comparison between groups was done by using Fisher, Chi-square and T-tests. Values less than 0.05 were considered statistically significant. 


\section{Results}

\section{Demographics and clinical measures}

We included a total of 42 fetuses with IUGR and 28 fetuses in the control group with similar gestational age (around 28-38 weeks) in this study. IUGR fetuses consisted of 24 fetuses in subtype A and 18 cases in subtype B. Maternal and fetal characteristics and perinatal outcome of the study groups are presented in table. 1. Only one death (stillbirth) in subtype A was reported.

UA PI $>95$ th centile, MCA PI < 5th centile and UtA PI > 95th centile were detected in $11(45 \%)$ fetuses, $4(16.6 \%)$ fetuses and $5(21 \%)$ cases with subtype A IUGR respectively. Absent or reversed diastolic flow in an umbilical artery or abnormal flow in ductus venosus were not found in any of IUGR subgroups (no cases with severe hypoxia).

\section{MRI examination}

Brain white and grey matter signal and morphology were normal in all fetuses and no obvious hypoxic ischemic events as hemorrhagic changes were detected. Corrected cortical thickness in the insula and temporal lobes were significantly thinner in the IUGR group in comparison with the control group (0.034 vs 0.043 and 0.036 vs 0.047 respectively, $\mathrm{P}$ value <0.05) (Figure. 3). But there was no significant difference in frontal and occipital lobes cortical thickness (Table. 2). Insular, frontal and occipital corrected cortical thickness was thinner in subtype A than subtype B but the difference was not significant (Table. 3).

IUGR fetuses have significantly smaller corrected WBA (0.806 vs $0.812, \mathrm{P}$ value 0.028$)$. The corrected area of the cerebellum and hippocampus were smaller in normally-grown fetuses $(0.130$ vs $0.147,0.0125 \mathrm{vs} 0.017$, respectively, $\mathrm{P}$ value of $<0.05$ ) (Figure 4), but other corrected areas of the brain were not significantly different between IUGR and control group (Table. 2). The 
corrected area of frontal, temporal, cerebellum and hippocampus in subtype A were smaller than subtype B but the difference was not significant (Table. 3).

\section{Discussion}

Our study has demonstrated that corrected cortical thickness in the insula and temporal lobes were significantly thinner in IUGR fetuses compared to the control group. Also, the whole brain area was significantly smaller in the IUGR group. Interestingly, the corrected areas of the cerebellum and hippocampus were smaller in controls.

Several studies suggest that IUGR due to placental insufficiency is associated with specific structural and functional changes in cortical development of the brain $(9,5)$. IUGR neonates have a delay in cortical development at birth and also have brain cortical thickness and volume reduction $(3,20)$.

The insula is a main part of the limbic system and has the main role in cognition and awareness (20). In our study, the corrected cortical thickness of insula is thinner in IUGR fetuses compared to the control group. Our results are compatible with Egana-Ugrinovic et al. study in which it was shown that IUGR fetuses have reduced insular cortical thickness compared to controls. The possible mechanism is that this area is vulnerable to long term hypoxia (8).

Moreover, our IUGR group had significantly thinner corrected temporal cortical thickness. Our results are in line with another study that showed bilateral reduced gray matter in the temporal lobe in IUGR fetuses compared with the controls (14). More researches need to be conducted to obtain a better interpretation of the effect of growth restriction on temporal cortical thickness. 
Our results show that the whole brain area in the IUGR group was significantly lower than controls and our findings are compatible with previous studies $(5,9,15,22)$. These differences may be due to the effect of placental insufficiency on DNA synthesis, reduction in brain cell size and number, synaptogenesis and total brain weight $(23,24)$. However, in contrast to the abovementioned studies, there was only one research that found no significant difference in whole brain volume between the IUGR and normal fetuses (25).

It is worth to note that in this research, the corrected area of the cerebellum was larger in the IUGR group compared to controls. We assessed the corrected area of the cerebellum by dividing the cerebellar area by whole brain area and as mentioned whole brain area in IUGR groups was smaller. This finding may show that the cerebellum is less affected by IUGR compared with other brain regions. Our results are approximately in line with a study by Sanz-Cortes et al., who assessed corrected cerebellar volume by dividing cerebellar volume to whole brain volume, they showed significantly larger cerebellar ratio in IUGR fetuses (26,27). In addition, Bruno et al showed that there was no significant difference in cerebellar volume between IUGR and control groups (27). Research using ultrasound also showed preservation of trans cerebellar diameter in IUGR fetuses (28). All the above-mentioned studies emphasize the preservation of cerebellar size in IUGR fetuses. However, research by Polat et al. found decreased cerebellar /supratentorial volume ratio in IUGR fetuses (29) and another study by Anderscavage et al. demonstrated smaller cerebellar volume in IUGR fetuses (30). Due to variable results, further studies are needed to evaluate the growth restriction effect on fetal cerebellum.

Hippocampus is an important grey matter structure and is sensitive to placental insufficiency, hypoxia, lower nutritional supply and maternal stress (31,32,33). An animal study showed adverse molecular and cellular effects of IUGR on hippocampus structures (34). Interestingly, in our study 
IUGR fetuses had significantly larger corrected hippocampus area and similar to the cerebellar area, this region may be less affected by IUGR. Padilla et al studied a sample of IUGR and AGA neonatal groups, they found no difference in hippocampus volume between these groups (15). On the contrary, Gregory et al. suggested that total hippocampal volume is affected by IUGR, they reported significantly smaller hippocampus volume in IUGR fetuses compared with controls (7).

Our study showed no statically significant correlation between frontal and occipital corrected areas among IUGR and control groups. No study was found to evaluate different brain lobe areas, but our study is in line with the research of padilla et al. that demonstrated similar frontal and occipital relative volumes between IUGR fetuses and controls (15). Some studies in older age showed smaller frontal lobe volumes in IUGR group and the difference in relative frontal volume may no longer observable up to 1 year old (15). On the other hand, a study using sonographic biometry showed decreased frontal dimension in IUGR neonates compared to controls (35). It has been demonstrated that the frontal lobe may have delayed growth pattern in IUGR (34). Considering these findings, the preservation of the frontal lobe area in IUGR fetuses of our study may be due to developmental process of frontal lobe and the lower gestational age of evaluation.

This study had some limitations. First, the sample size was relatively small, especially for comparing the faint differences between IUGR subtypes. Second, we manually traced all brain areas and it could be subject to inter or intra-reader variability. Third, the number of IUGR fetuses and control group were not similar. The most non-IUGR cases referred for fetal MRI at lower gestational age opposite to the IUGR cases. Therefore, for matching the gestational age of two groups we had limitation in including of control fetuses. And at the end, because our control group had been selected from fetuses with other pathologies, the post-natal outcome was not different between IUGR and control groups. 


\section{Conclusion}

Our study shows that IUGR has selective effects on brain morphometrics. IUGR fetuses have a thinner cortical thickness in insular and temporal lobes and smaller whole brain areas. Furthermore, cerebellum and hippocampus were less affected by growth restriction. Further detailed investigations in the future will be needed to evaluate morphometrics effects of IUGR on the insula, cerebellum, hippocampus, and temporal lobe and its association with neurological outcome.

\section{Acknowledgments}

This study was financially supported by the Radiology research center, Imam Khomeini Hospital, Tehran, Iran (grant number: 98-01-98-41442)

\section{References:}

1. Batalle D, Eixarch E, Figueras F, et al. Altered small-world topology of structural brain networks in infants with intrauterine growth restriction and its association with later neurodevelopmental outcome. Neuroimage. 2012 Apr 2;60(2):1352-66.

2. Malhotra A, Allison BJ, Jenkin G, Polglase GR, Miller SL. Neonatal morbidities of fetal growth restriction: pathophysiology and impact. Frontiers in endocrinology. 2019; 10:55

3. Dubois J, Benders M, Borradori-Tolsa C, et al. Primary cortical folding in the human newborn: an early marker of later functional development. Brain. 2008 Jun 28;131(8):2028-41.

4. Toft PB, Leth H, Ring PB, Peitersen B, Lou HC, Henriksen O. Volumetric analysis of the intrauterine growth retardation. Early human development. 1995 Aug normal infant brain and in 30;43(1):15-29. 
5. Tolsa CB, Zimine S, Warfield SK, et al. Early alteration of structural and functional brain development in premature infants born with intrauterine growth restriction. Pediatric research. 2004 Jul;56(1):132.

6. Arthurs OJ, Rega A, Guimiot F, et al. Diffusion-weighted magnetic resonance imaging of the fetal brain in intrauterine growth restriction. Ultrasound in Obstetrics \& Gynecology. 2017 Jul;50(1):79-87.

7. Lodygensky GA, Seghier ML, Warfield SK, et al. Intrauterine growth restriction affects the preterm infant's hippocampus. Pediatric research. 2008 Apr;63(4):438.

\section{Egana-Ugrinovic G, Sanz-Cortes M, Figueras F, Couve-Perez C, Gratacos E. Fetal MRI} insular cortical morphometry and its association with neurobehavior in late-onset small-forgestational-age fetuses. Ultrasound in Obstetrics \& Gynecology. 2014 Sep;44(3):322-9.

9. Egaña-Ugrinovic G, Sanz-Cortes M, Figueras F,et al. Differences in cortical development assessed by fetal MRI in late-onset intrauterine growth restriction. American journal of obstetrics and gynecology. 2013 Aug 1;209(2):126-e1.

10. Malhotra A, Ditchfield M, Fahey MC, Castillo-Melendez M, Allison BJ, Polglase GR, Wallace EM, Hodges R, Jenkin G, Miller SL. Detection and assessment of brain injury in the growth-restricted fetus and neonate. Pediatric research. 2017 Aug;82(2):184.

11. Eixarch E, Batalle D, Illa M, et al. Neonatal neurobehavior and diffusion MRI changes in brain reorganization due to intrauterine growth restriction in a rabbit model. PloS one. $2012 \mathrm{Feb}$ 8;7(2):e31497.

12. Moradi, B, Alibeigi nezhad Z, Seyed Saadat, Shirazi M, Borhani A, Kazemi MA. Apparent Diffusion Coefficient of Different Areas of Brain in Fetuses with Intrauterine Growth Restriction. .Pol J Radiol. 2020; 85: e301-e308

13. Sanz-Cortes M, Ratta GA, Figueras F, et al. Automatic quantitative MRI texture analysis in small-for-gestational-age fetuses discriminates abnormal neonatal neurobehavior. PloS one. $2013 \mathrm{Jul}$ 26;8(7):e69595.

\section{Egaña-Ugrinovic G, Sanz-Cortés M, Couve-Pérez C, Figueras F, Gratacós E. Corpus} callosum differences assessed by fetal MRI in late-onset intrauterine growth restriction and its association with neurobehavior. Prenatal diagnosis. 2014 Sep;34(9):843-9.

15. Padilla N, Falcón C, Sanz-Cortés M, et al. Differential effects of intrauterine growth restriction on brain structure and development in preterm infants: a magnetic resonance imaging study. Brain research. 2011 Mar 25;1382:98-108.

16. Kiserud T, Piaggio G, Carroli G,et al. The World Health Organization fetal growth charts: a multinational longitudinal study of ultrasound biometric measurements and estimated fetal weight. PLoS medicine. 2017 Jan 24;14(1):e1002220. 


\section{ACR-SPR PRACTICE PARAMETER FOR THE SAFE AND OPTIMAL} PERFORMANCE OF FETAL MAGNETIC RESONANCE IMAGING (MRI). Resvised 2015.

18. Ciobanu A, Wright A, Syngelaki A, Wright D, Akolekar R, Nicolaides KH. Fetal Medicine Foundation reference ranges for umbilical artery and middle cerebral artery pulsatility index and cerebroplacental ratio. Ultrasound in Obstetrics \& Gynecology. 2019 Apr;53(4):465-72.

19. Melchiorre K, Leslie K, Prefumo F, Bhide A, Thilaganathan B. First-trimester uterine artery Doppler indices in the prediction of small-for-gestational age pregnancy and intrauterine growth restriction. Ultrasound in Obstetrics and Gynecology: The Official Journal of the International Society of Ultrasound in Obstetrics and Gynecology. 2009 May;33(5):524-9.

20. Samuelsen GB, Pakkenberg B, Bogdanović N, et al. Severe cell reduction in the future brain cortex in human growth-restricted fetuses and infants. American journal of obstetrics and gynecology. 2007 Jul 1;197(1):56-e1.

21. Uddin LQ, Nomi JS, Hébert-Seropian B, Ghaziri J, Boucher O. Structure and function of the human insula. Journal of clinical neurophysiology: official publication of the American Electroencephalographic Society. 2017 Jul;34(4):300.

22. Simões RV, Muñoz-Moreno E, Cruz-Lemini M, et al. Brain metabolite alterations in infants born preterm with intrauterine growth restriction: association with structural changes and neurodevelopmental outcome. American journal of obstetrics and gynecology. 2017 Jan 1;216(1):62-e1.

23. Lupien SJ, McEwen BS, Gunnar MR, Heim C. Effects of stress throughout the lifespan on the brain, behaviour and cognition. Nature reviews neuroscience. 2009 Jun;10(6):434.

24. Mallard EC, Rees S, Stringer M, Cock ML, Harding R. Effects of chronic placental insufficiency on brain development in fetal sheep. Pediatric Research. 1998 Feb;43(2):262.

25. Damodaram MS, Story L, Eixarch E, et al. Foetal volumetry using magnetic resonance imaging in intrauterine growth restriction. Early human development. 2012 Mar 1;88:S35-40.

26. Sanz-Cortes M, Egana-Ugrinovic G, Zupan R, Figueras F, Gratacos E. Brainstem and cerebellar differences and their association with neurobehavior in term small-for-gestational-age fetuses assessed by fetal MRI. American journal of obstetrics and gynecology. 2014 May 1;210(5):452-e1.

27. Bruno CJ, Bengani S, Gomes WA, et al. MRI differences associated with intrauterine growth restriction in preterm infants. Neonatology. 2017;111(4):317-23.

28. Park M, Kim H. Frontal lobe and cerebellar differences in IUGR and AGA fetuses. Ultrasound in Obstetrics \& Gynecology. 2016 Sep;48:226.

29. Polat A, Barlow S, Ber R, Achiron R, Katorza E. Volumetric MRI study of the intrauterine growth restriction fetal brain. European radiology. 2017 May 1;27(5):2110-8. 
30. Andescavage N, Metzler M, Bulas D, et al. In vivo assessment of placental and brain volumes in growth-restricted fetuses with and without fetal Doppler changes using quantitative 3D MRI. Journal of Perinatology. 2017 Dec;37(12):1278.

31. Mallard EC, Rehn A, Rees S, Tolcos M, Copolov D. Ventriculomegaly and reduced hippocampal volume following intrauterine growth-restriction: implications for the aetiology of schizophrenia. Schizophrenia research. 1999 Nov 9;40(1):11-21.

32. Mallard C, Loeliger M, Copolov D, Rees S. Reduced number of neurons in the hippocampus and the cerebellum in the postnatal guinea-pig following intrauterine growth-restriction.

Neuroscience. 2000 Sep 14;100(2):327-33.

33. Cumberland AL, Palliser HK, Rani P, Walker DW, Hirst JJ. Effects of combined IUGR and prenatal stress on the development of the hippocampus in a fetal guinea pig model. Journal of developmental origins of health and disease. 2017 Oct;8(5):584-96.

34. Ruff CA, Faulkner SD, Rumajogee P,et al. The extent of intrauterine growth restriction determines the severity of cerebral injury and neurobehavioural deficits in rodents. PloS one. 2017 Sep 21;12(9): e0184653.

35. Makhoul I R, Soudack M, Goldstein I, Smolkin T, Tamir A, Sujov P. (2004). Sonographic biometry of the frontal lobe in normal and growth-restricted neonates. Pediatric research.2004 may; $55(5): 877$.

Table1: Maternal and fetal characteristics and perinatal outcome of the study groups

\begin{tabular}{ccccccc}
\hline & $\begin{array}{c}\text { Group A IUGR } \\
\mathrm{n}=24\end{array}$ & $\begin{array}{c}\text { Group B } \\
\text { IUGR } \\
\mathrm{n}=18\end{array}$ & P Value & $\begin{array}{c}\text { IUGR } \\
\mathrm{n}=42\end{array}$ & $\begin{array}{c}\text { Control group } \\
\mathrm{n}=28\end{array}$ & P Value \\
\hline Maternal & & & & & & \\
Characteristics & & & & & & \\
\hline Age(y) & $29.33 \pm 5.53$ & $30.39 \pm 4.94$ & 0.593 & $29.79 \pm 5.25$ & $29.81 \pm 2.67$ & 0.792 \\
Height(cm) & $162.04 \pm 5.57$ & $161.28 \pm 4.35$ & 0.768 & $161.71 \pm 5.04$ & $157.64 \pm 14.63$ & 0.470 \\
Weight(kg) & $77.37 \pm 15.09$ & $77 \pm 12.20$ & 0.932 & $77.21 \pm 13.77$ & $73.43 \pm 12.52$ & 0.247 \\
BMI (kg/m2) & $29.44 \pm 5.47$ & $29.63 \pm 4.75$ & 0.903 & $29.52 \pm 5.11$ & $28.15 \pm 4.41$ & 0.250 \\
Preeclampsia & $4(16.7 \%)$ & $1(5.6 \%)$ & $\mathbf{0 . 0 2}$ & $5(11.9 \%)$ & $0(0 \%)$ & $\mathbf{0 . 0 0 1}$ \\
\hline Fetal & & & & & & \\
Characteristic & & $34+6$ & & & & \\
\hline Age(wks) & $33+6$ & $34+1$ & 0.690 & $34+1$ & 34 & 0.98 \\
Weight(gr) & $1704.83 \pm 487.7$ & $1829.1 \pm 562.8$ & 0.448 & $1758 \pm 517.8$ & $1954 \pm 662$ & 0.157 \\
Sex (female) & $12(50 \%)$ & $10(55 / 6 \%)$ & 0.721 & $22(52 / 4 \%)$ & $6(21 / 4 \%)$ & $\mathbf{0 . 0 1 0}$ \\
HC<5\% & $13(54 / 2 \%)$ & $4(22.2 \%)$ & $\mathbf{0 . 0 0 0 2}$ & $17(40 \%)$ & $0(0 \%)$ & $\mathbf{0 . 0 0 0 1 >}$ \\
\hline
\end{tabular}


medRxiv preprint doi: https://doi.org/10.1101/2020.10.31.20222737; this version posted November 4, 2020. The copyright holder for this preprint (which was not certified by peer review) is the author/funder, who has granted medRxiv a license to display the preprint in perpetuity.

It is made available under a CC-BY-ND 4.0 International license .

\begin{tabular}{ccccccc}
\hline $\begin{array}{c}\text { Perinatal } \\
\text { outcome }\end{array}$ & & & & & \\
\hline $\begin{array}{c}\text { Birth Weight } \\
(\mathrm{g})\end{array}$ & $2194.76 \pm 544.98$ & $2616.3 \pm 363.4$ & $\mathbf{0 . 0 1 1}$ & $2377.1 \pm 514.6$ & $2965.7 \pm 733.13$ & $\mathbf{0 . 0 0 0 1 <}$ \\
$\begin{array}{c}\text { GA at birth } \\
(\mathrm{wks})\end{array}$ & $36+6$ & $37+2$ & 0.330 & $37+1$ & $37+2$ & 0.978 \\
$\quad \begin{array}{l}\text { NICU } \\
\text { Admission }\end{array}$ & $8(38.1 \%)$ & $3(18.8 \%)$ & $\mathbf{0 . 0 1 2}$ & $11(29.7 \%)$ & $8(28.6 \%)$ & 0.89 \\
$\begin{array}{l}\text { Intrauterine still } \\
\text { birth }\end{array}$ & $1(5 \%)$ & $0(0 \%)$ & 1 & $1(2.9 \%)$ & $0(0 \%)$ & 1 \\
\hline $\begin{array}{l}\text { BMI, body mass index; HC, head circumference; GA, gestational age; IUGR, intrauterine growth restricted; } \\
\text { NICU, neonatal intensive care unit }\end{array}$ &
\end{tabular}

Table 2: Corrected brain area and corrected cortical thickness in IUGR group and controls

\begin{tabular}{cccc}
\hline & $\begin{array}{c}\text { IUGR } \\
\mathrm{n}=42\end{array}$ & $\begin{array}{c}\text { Control group } \\
\mathrm{n}=28\end{array}$ & P Value \\
& & & \\
\hline Cortical thickness(mm) & & & \\
\hline Insula & $0.034 \pm 0.007$ & $0.043 \pm 0.012$ & $\mathbf{0 . 0 0 1}$ \\
Frontal lobe & $0.031 \pm 0.005$ & $0.033 \pm 0.013$ & 0.250 \\
Occipital lobe & $0.031 \pm 0.007$ & $0.034 \pm 0.013$ & $\mathbf{0 . 0 1 0}$ \\
Temporal lobe & $0.036 \pm 0.007$ & $0.047 \pm 0.027$ & 0.374 \\
Area(cm2) & & & 0.611 \\
\hline Frontal lobe & $0.214 \pm 0.028$ & $0.209 \pm 0.029$ & 0.274 \\
Temporal lobe & $0.086 \pm 0.024$ & $0.086 \pm 0.022$ & $\mathbf{0 . 0 0 1}>$ \\
Occipital lobe & $0.105 \pm 0.024$ & $0.100 \pm 0.016$ & $\mathbf{0 . 0 0 1}$ \\
Hippocampus & $0.017 \pm 0.008$ & $0.0125 \pm 0.003$ & 0.983 \\
Cerebellum & $0.147 \pm 0.021$ & $0.130 \pm 0.019$ & 1 \\
Midbrain & $0.043 \pm 0.015$ & $0.043 \pm 0.007$ & $\mathbf{0 . 0 2 8}$ \\
Pons & $0.031 \pm 0.014$ & $0.028 \pm 0.003$ &
\end{tabular}


Table 3: Difference of corrected brain area and corrected cortical thickness in group A IUGR and group B IUGR

$\begin{array}{ccc}\underset{n}{\text { Group A IUGR }} & \text { Group B IUGR } & \text { P Value } \\ \mathrm{n}=18 & \end{array}$

\begin{tabular}{cccc}
\hline Cortical thickness $(\mathbf{m m})$ & & & \\
\hline Insula & $0.032 \pm 0.005$ & $0.036 \pm 0.009$ & 0.104 \\
Frontal lobe & $0.029 \pm 0.003$ & $0.032 \pm 0.007$ & 0.104 \\
Occipital lobe & $0.030 \pm 0.006$ & $0.032 \pm 0.007$ & 0.562 \\
Temporal lobe & $0.037 \pm 0.006$ & $0.036 \pm 0.007$ & 0.415 \\
\hline Area(cm2) & & & 0.169 \\
Frontal lobe & $0.208 \pm 0.029$ & $0.222 \pm 0.024$ & 0.668 \\
Temporal lobe & $0.085 \pm 0.015$ & $0.088 \pm 0.034$ & 0.627 \\
Occipital lobe & $0.105 \pm 0.021$ & $0.105 \pm 0.028$ & 0.334 \\
Hippocampus & $0.015 \pm 0.003$ & $0.019 \pm 0.012$ & 0.791 \\
Cerebellum & $0.146 \pm 0.022$ & $0.148 \pm 0.019$ & 0.368 \\
Midbrain & $0.045 \pm 0.019$ & $0.041 \pm 0.007$ & 0.44 \\
Pons & $0.028 \pm 0.011$ & $0.034 \pm 0.017$ & 0.566
\end{tabular}


medRxiv preprint doi: https://doi.org/10.1101/2020.10.31.20222737; this version posted November 4, 2020. The copyright holder for this preprint (which was not certified by peer review) is the author/funder, who has granted medRxiv a license to display the preprint in perpetuity.

It is made available under a CC-BY-ND 4.0 International license .

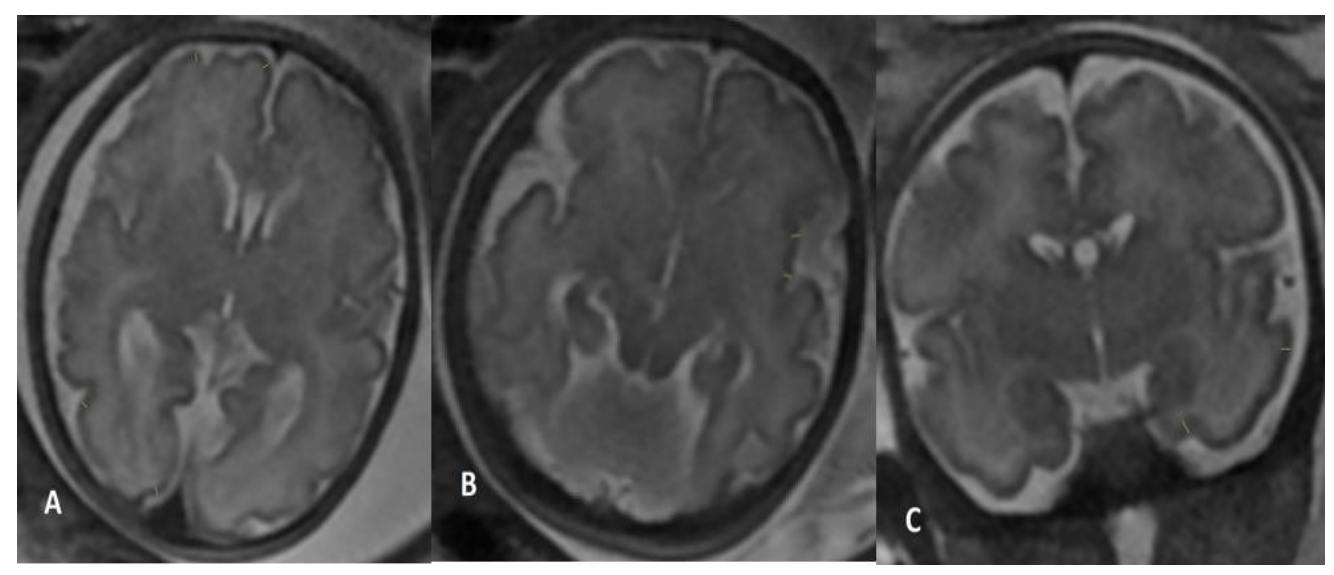

Figure. 1

T2-Weighted magnetic resonance images show brain cortical thickness assessment.

(a) Frontal and occipital lobes cortical thickness measurement (in the axial plane at the level of cavum septum pellucidum), (b) Insular cortical thickness measurement (in the axial plane just below the plane of cavum septum pellucidum), (c)Temporal lobe cortical thickness measurement (In the coronal plane, just anterior slice to pons level). Two parts of them were measured from inner to outer 

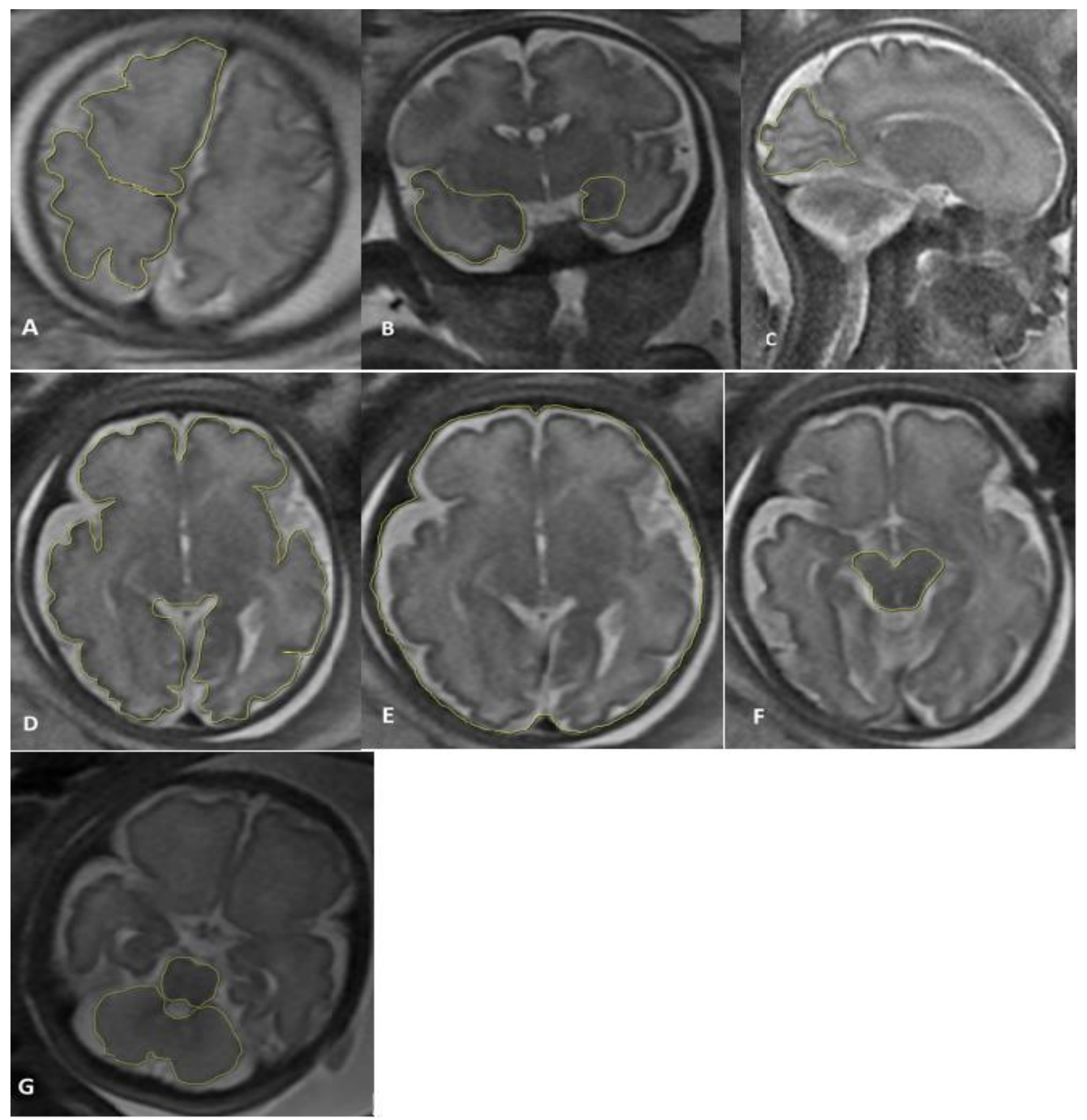

Figure. 2

T2-Weighted magnetic resonance images demonstrate different brain lobe area assessments. (a) Frontal and parietal lobe areas (in the axial plane, just superior to cavum septum pellucidum and lateral ventricles), (b) Temporal lobe area (in the coronal plane, just anterior to the pons level), (c) Occipital lobe area (in the first para-sagittal plane, near falx, posterior to the parieto-occipital sulcus), (d) Whole brain area (in the axial plane at the level of cavum septum pellucidum), (e) Whole intracranial area (at the same level of WBA by tracing cursor inside the bony calvarium), (f) Midbrain area, (g) Cerebellum and pons areas (in the axial plane, at the level of the middle cerebellar peduncle). 


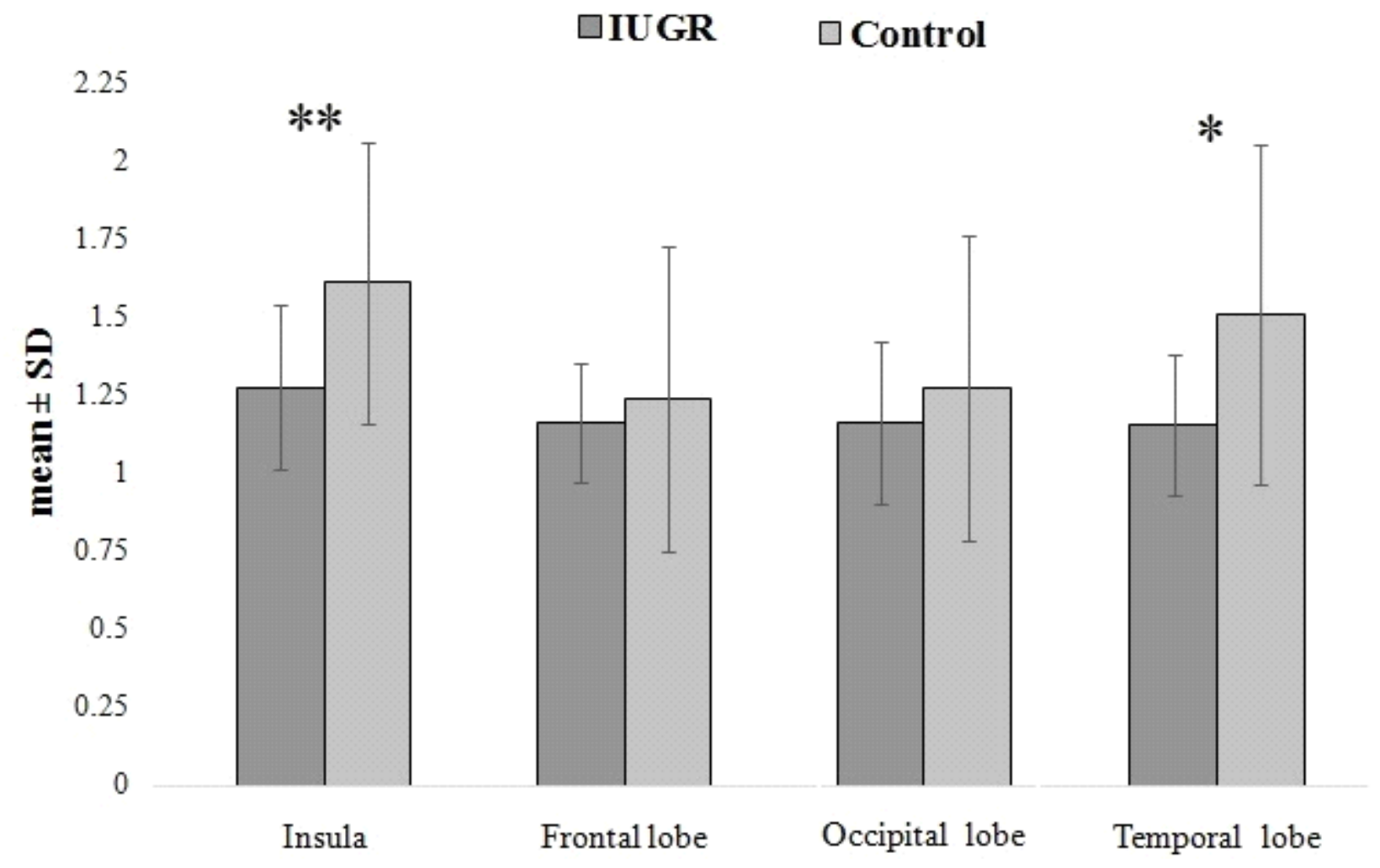

Figure 3

The polynomial contrast analysis figure demonstrates the difference of corrected cortical thickness in different brain regions between the IUGR group and Controls. The bars show mean \pm SD for each group. Asterisks demonstrate $\mathrm{P}<0.05$ 


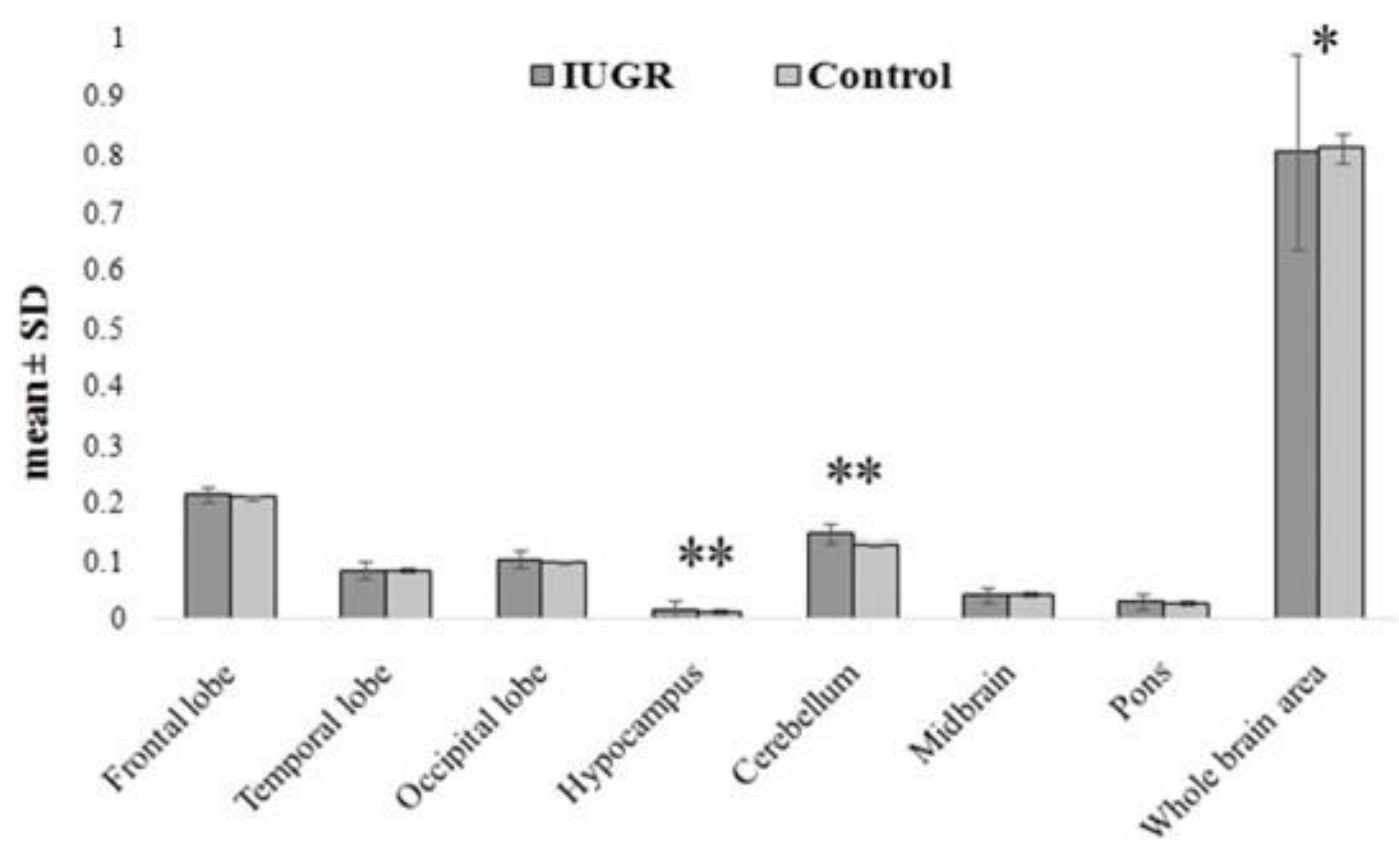

\section{Figure 4}

The polynomial contrast analysis figure demonstrates the difference between corrected brain areas in different lobes between the IUGR group and controls. The bars show mean \pm SD for each group. Asterisks demonstrate $\mathrm{P}<0.05$ 
medRxiv preprint doi: https://doi.org/10.1101/2020.10.31.20222737; this version posted November 4, 2020. The copyright holder for this preprint (which was not certified by peer review) is the author/funder, who has granted medRxiv a license to display the preprint in perpetuity.

It is made available under a CC-BY-ND 4.0 International license. 